\title{
The excessive use of social media and its relationship to insomnia among female students in Hail University
}

\author{
Halima Mohamed, Adam \\ Ph.D. Clinical Psychology \\ Assistant Professor, Psychology department, Hail University, KSA \\ halowadam2@gmail.com




$$
\text { المجلة الدولية للدراسات التربوية والنفسية }
$$

International Journal of Educational \& Psychological Studies (EPS)

Journal Homepage: https://www.refaad.com/views/EPSR/Home.aspx

ISSN: 2520-4149 (Online) 2520-4130 (Print)

\title{
The excessive use of social media and its relationship to insomnia among female students in Hail University
}

\author{
Halima Mohamed, Adam \\ Ph.D. Clinical Psychology \\ Assistant Professor, Psychology department, Hail University, KSA \\ halowadam2@gmail.com
}

Received: 30/10/2020 Revised: 17/11/2020 Accepted: 20/12/2020 DOI: https://doi.org/10.31559/EPS2021.9.3.16

\begin{abstract}
:
The purpose of preparing this research paper is to explain the relationship between the excessive social media use and insomnia disorder among female students in Hail University, although identifying the differences in excessive use, and insomnia among the sample members.

The descriptive-correlational approach was followed, and the sample was chosen in a stratified random manner, as the sample reached 360 students from various disciplines. Social media behavioral addiction indices were measured using the Social Media Usage Scale (SMU), and insomnia disorder measured using an (ID) scale. The results of the study show that there is a statistical correlation between the use of social media and insomnia disorders. Well as the relationship between the type of social media and the number of accounts and preferred social media and insomnia disorders, and the value of each was $<0.05$. The study concluded that female university students suffer from excessive use of social media, which negatively affected the quality of sleep and their mood.
\end{abstract}

Keywords. Social media; Insomnia disorder; Excessive use.

\section{Introduction}

Social media has become a lifestyle for most generations around the world, the harm to health social media use is greater than we used to. The excessive use of social media has made many people suffer from depression and insomnia (Kirk\& Steijn, 2014). More than 4.5 billion people use the Internet in 2020, while social media users exceeded 3.8 billion, an increase of more than 9 percent since this time last year (Chaffey, 2020). According to the Saudi ministry of communications and information technology (2020), the interest of the Saudi people in social media has increased, and their impact on their daily lives has increased. The number of users has reached 18.3 million, equivalent to $58 \%$ of the population of the kingdom of Saudi Arabia. The average login to social networks is 260 minutes per day per person. Just as Facebook and Twitter dominate the largest number of social media users in the Kingdom, Saudi Arabia is the first Arab and the second globally to use Snapchat. WhatsApp and Facebook had the top rates of social networking platforms use. Travelodge (2014) surveyed 6000 adults to explore what the British did before bed. It was discovered that $70 \%$ of adults send a tweet every night to their followers and $20 \%$ follow their friends' tweets and favorite celebs. On average, people spend 16 minutes a night on the bed on social media, and this, as well as on their sleep patterns.

Insomnia can be defined as the disorder of a combination of day and night symptoms. Characterized by complaining of dissatisfaction with the quality or duration of sleep with difficulty in starting sleep on time, waking up frequently or for a long time, or waking up early with the inability to return to sleep (DSM-5,2013). Both Kraemer (2001) and Kazdin (2007) state that there is a group of associations which constitute a risk factor in insomnia, such as social and demographic factors, and include advanced age, female, low socioeconomic status, unemployment, low educational attainment, psychological distress, and self-categorized poor health. Morin and

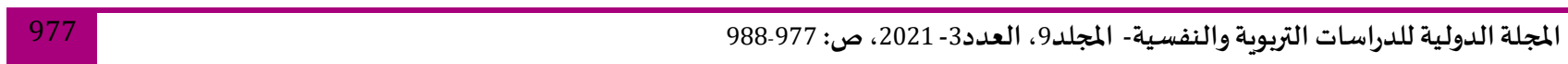


his colleagues (2015) draw the attention to the fact that chronic insomnia is associated with several psychological and medical difficulties that lead to a lower quality of life, and a somewhat lower performance in all areas of work, which makes productivity and efficiency a significant risk to poor personal performance, and poor social relations resulting in life dissatisfaction. Jennifer and her colleagues' study (2013) showed that first-year female college students spend 12 hours using media daily. This excessive use has negatively affected their academic performance. The results of The Bhat study (2017) confirm that in-bed mobile device-related electronic social media's use is associated with adverse sleep and mood outcomes in adults. Comparing teenagers and young adults to other age groups, it is deducted that they are more likely to stay up late, report shorter sleep duration on weekdays, delayed sleep with extended sleep on weekends. The evening use of social media is more associated with poor sleep quality, extreme insomnia, and more psychological distress and daytime drowsiness (Bakotic \& other,2017).

In this study, the researcher tries to explain what is the relationship between excessive use of social media, and insomnia, in addition to the factors that may make a difference.

\section{Problem of study}

The year 2020 witnessed an increase in the number of users of the Internet, reaching 6.8 billion people (Ericsson,2019), and social media such as Facebook, Twitter are considered the most used (Settanni,2018). Social media has replaced the traditional way of social communication $(\mathrm{Cao}, 2019)$ and has become an environment conducive to learning, acquisition of skills, and entertainment. Although social media allow users to express feelings and emotional catharsis, they may cause psychological disorders as a result of overexposure (Back,,2010). which may increase feelings of dissatisfaction and cause impairment in various important aspects of users' lives. the problem of the study is summarized in this question:

What is the relationship between the excessive use of social media and insomnia disorder among students of the University of Hail?

\section{Aim of study}

The aims of the study are as follows:

1. Identify the relationship between excessive use of social media and insomnia.

2. Check the differences in insomnia according to the number of accounts on social media and the preferred account.

3. Clarify the differences in excessive use according to demographic variables.

\section{The Importance of Research:}

1. Expand the knowledge base related to the impact of excessive use of social media.

2. Providing mental health professionals and academics with information on aspects affecting the mental health of undergraduate students.

3. The study contributes to identifying the reasons that lead to a decline in students' academic performance.

\section{Materials and methods}

\section{Method:}

The researcher used the descriptive-correlational approach for its relevance to the study problem and its hypotheses.

\section{Participants:}

This study was approved by the governing councils of the Department of Psychology, the College of Education, the Research Ethics Committee at the University of Hail, and institutional review boards in the Deanship of Scientific Research. Prior informed consent was obtained from all participants. The data was collected confidentially by using an online questionnaire, all the university students are participating in interactive groups on WhatsApp, a promotional message was sent explaining the purpose of the study and contains a link to the online survey site. Students were motivated to participate in the study by sending reminders to the groups of the targeted colleges.

The sample of the study consisted of 360 students who were divided into three tracks, they were selected randomly stratified by $3 \%$ of each layer, the Humanities $(n=140)$, the Engineering $(n=100)$ and the Medical $(n$ $=120$ ) The percentage of participants according to academic specializations was $39 \%$ for Humanities, $27 \%$ for engineering, and 34\% for medical. The study levels of the participants varied from the first to the sixth level, where the highest participation rate for the fourth level students was $32.5 \%$. The ages of the participants ranged from 17 to 25 years, and among participants of the 20-22 age group, by 55\%. The marital status of the sample members varied from unmarried, married, divorced, and widows. The majority of the sample members were

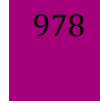


unmarried, with a percentage of $82.5 \%$. The grade point average (GBA) of female students ranged from 1 to 4 points, and $37.5 \%$ of the sample got $3.1-3.5$ points.

The data were collected within six months from October 2019 to March 2020.

\section{Instruments:}

All study participants completed a questionnaire consisting of 77 subjects via the Internet. The first nine questions collected demographic data such as (age, marital status, specialization, GBA, and the number of accounts) see table (1).

\begin{tabular}{clll} 
& \multicolumn{2}{c}{ Table (1): Demographic variables } & \\
\hline Demographic variables & & Frequency & Percent \% \\
\hline Age & $17-19$ & 18 & 55 \\
& $20-22$ & 198 & 37.5 \\
& $23-25$ & 135 & 2.5 \\
\hline Marital status & $<25$ & 9 & 82.5 \\
& Unmarried & 297 & 7.5 \\
& engaged & 27 & 7.5 \\
& Married & 27 & 2.5 \\
\hline Dcademic specialization & Divorced & 9 & 39 \\
& humans & 140 & 27 \\
& engineering & 100 & 34 \\
\hline GBA & medical & 120 & 2.5 \\
& $1-1.5$ & 9 & 5 \\
& $1.6-2$ & 18 & 5 \\
& $2.1-2.5$ & 18 & 30 \\
& $2.6-3$ & 108 & 37.5 \\
& $3.1-3.5$ & 135 & 20 \\
\hline $3.6-4$ & 72 & \\
\hline
\end{tabular}

Insomnia was measured across the insomnia disorder scale (I D):

The (ID) scale consists of 30 items representing 8 main dimensions, the scale consists of two parts; (A) and (B). Part (A) deals with 4 questions that determine the severity and duration of the disorder and whether the disorder is due to other disorders. As for part (B), it consists of 26 statements dealing with the nine of the dimensions; (complaining about dissatisfaction with the amount or quality of sleep, the decrease or noticeable frustration in performance areas, difficulty sleeping occurs at least 3 nights per week, difficulty sleeping is present for a period at least 3 months, sleep difficulty occurs despite adequate opportunity, insomnia does not occur due to another sleep disturbance, insomnia is not due to misuse of a substance or medication, insomnia does not explain due to the mental disorders or medical conditions).

They are corrected by the five-gradient. The highest degree that can be obtained Screened 144 and the below is 30 , high scores on the scale indicate the severity of the disorder, and the severity ranges from mild, moderate, to severe. This scale is an ultra-sharp instrument with approval, the scale is based on diagnostic criteria according to the Fifth Diagnostic and Statistical Manual (DSM-5).

The validity of the internal consistency of the scale was verified by calculating the Pearson correlation coefficient between the scores of the scale and the total score. The correlation coefficient for the paragraphs ranged between (.242) as a minimum and (.838) as a maximum at a level of 0.01 significance. Therefore, all the paragraphs of the scale are internally consistent which proves the validity of the scale to conduct the study

To measure the reliability of the scale, Cronbach's Alpha was used and the total reliability degree was (.820). The reliability was verified using the Guttman split-half Coefficient and the reliability score was (.825), which indicates that the scale has a high-reliability degree that can be relied on.

\section{The Social Media Use scale (S M U):}

The excessive use of social media has been verified by using (SMU), It consists of 38 items, with 8 dimensions compatible with the Criteria for diagnosing behavioral addiction: preoccupation, negative mood management, Tolerance, withdrawal, consequences, relapse or control, craving, and hiding use. The number of items differed in the eight dimensions of the scale according to the number of symptoms in them, the first dimension consists of 4 items, the second dimension 6 items, the third dimension 6 items, the fourth dimension 4 items, the fifth dimension 7 items / the previous dimension 3 items, and the eighth dimension 3 items.

Score from 1 to 5, with a breakpoint of 3. The grades are interpreted and their clinical significance is explained according to none excessive use, through mild, moderate, and severe. the lowest score for the scale is 38 , 
which expresses the normal level of use, while the scores from 39 to 76 mean mild use, from 77 to 114 indicates moderate use, and from 152 to 190 means severe use.

To verify the validity, the Pearson correlation coefficient was used to verify the integrity of the internal consistency of the paragraphs. The results of this procedure showed the saturation of all paragraphs and were statistically significant. The correlation coefficient for the items ranged between (.383) as a minimum and (.883) as a maximum at a level of 0.01 significance. Therefore, all the scale paragraphs are internally consistent, which proves the validity of the items. So, this scale is suitable for conducting the study

To identify the reliability of the scale, Cronbach's Alpha was used and the total reliability degree was (.970). The reliability was verified using the Spearman-Brown Coefficient and the degree of reliability was (.914), which indicates that the scale has a high stability degree that can be relied on in this conducting study.

\section{Statistical analysis:}

Parametric tests were used for the analysis. Correlations between variables were tested using the Pearson Correlation test Coefficient. Comparisons between groups were made using one-way (ANOVA) analysis and ANOVA tow - way analysis of variance to compare categorical variables. To discover the interactions between the different variables, the multiple subsequent comparisons tests were used.

Cronbach's Alpha, Guttman split-half Coefficient, and Spearman-Brown Coefficient were used to verify the validity of the tools' study, all calculations were performed using SPSS for Windows v24 (IBM Corporation, Armonk, New York) on Windows 10 / PC.

\section{Result}

\section{Theme I: the relationship between excessive use and insomnia}

Table (2): Correlation between excessive use of social media and insomnia

\begin{tabular}{cccccc}
\hline variables & $\mathrm{N}$ & Mean & Std. Deviation & $\begin{array}{c}\text { Pearson } \\
\text { Correlation }\end{array}$ & Sig. (2-tailed) \\
\hline $\begin{array}{c}\text { excessive use of } \\
\text { social media } \\
\text { Insomnia Disorder }\end{array}$ & 360 & 112.88 & 29.318 & $.333^{* *}$ & .000 \\
\hline
\end{tabular}

To ensure a statistically significant correlation between excessive use of social media and insomnia, the Pearson Correlation coefficient was used, and it was found that $\mathrm{R}=333$, at the significance level $=.000$, which confirms the existence of a statistical correlation is significant at the 0.01 level, Table (2) shows that.

Table (3): The correlation coefficient value R Square

\begin{tabular}{|c|c|c|c|c|c|c|}
\hline \multirow[b]{2}{*}{ odel } & & \multicolumn{2}{|c|}{ Unstandardized Coefficients } & \multirow{2}{*}{$\begin{array}{c}\text { Standardized } \\
\text { Coefficients Beta }\end{array}$} & \multirow[t]{2}{*}{$\mathrm{t}$} & \multirow[t]{2}{*}{ sig } \\
\hline & & B & Std. Error & & & \\
\hline & (Constant) & 64.838 & .2 .659 & .333 & 24.383 & .000 \\
\hline & $\begin{array}{l}\text { excessive use of social } \\
\text { media }\end{array}$ & .152 & .023 & & 6.687 & .000 \\
\hline
\end{tabular}

To explain the relationship between the independent and dependent variable, the correlation matrix was used by using the simple linear regression square, we find the complete correlation between the independent and dependent variable and that the correlation coefficient value $\mathrm{R}$ Square $=(.111)$ Adjusted $\mathrm{R}$ Square $=.109$. Referring to Table (3), it is clear that the excessive use variable caused the significance of the analysis of the variance of the regression at the significance level $=.000$

\section{Theme II :The relationship between insomnia and social media use factors}

To identify the relationship between the dependent and independent variables, the standard multiple linear regression coefficients were used.

Table (4): The relationship between dependent and independent variables

\begin{tabular}{cccccc}
\hline variables & & insomnia & number of accounts & GPA & preferred accounts \\
\hline Pearson & insomnia & 1.000 & .383 & $-.228-$ & .132 \\
& number of accounts & .383 & 1.000 & .145 & $-.214-$ \\
& GPA & $-.228-$ & .145 & -.1000 & 1.00 \\
& preferred accounts & .132 & $-.214-$ & .000 & .003 \\
\hline Sig. (1-tailed) & insomnia &. & .000 & .006 & .000 \\
& number of accounts & .000 & .003 & .021 & .000 \\
\hline
\end{tabular}


Table (4), which represents the correlation matrix between the various variables, shows that the relationship between insomnia and the number of accounts $=.383$ at the significance level of .000 , while the preferred social media variable is related insomnia with a degree of .132 and the significance level $=.006$, and we find that the GPA of female students is related to insomnia inversely $=-228$ - and the significance level .000 .

The correlation coefficient between the dependent variable and the independent variables combined, the correlation coefficient between them $=517$.

Table (5): ANOVA for analysis of variance between the variables

\begin{tabular}{lccccc}
\hline Model & Sum of Squares & $\mathrm{df}$ & Mean Square & $\mathrm{F}$ & Sig \\
\hline Regression & 17278.502 & 3 & 5759.501 & 43.311 & $.000 \mathrm{~b}$ \\
Residual & 47340.598 & 356 & 132.979 & & \\
Total & 64619.100 & 359 & & & \\
\hline
\end{tabular}

a. Dependent Variable: insomnia

b. b. Predictors: (Constant), number of accounts, GPA, preferred accounts

Table (5) explains the variance between the variables, the value of $\mathrm{F}=43.311$, at the level of significance of .000 , which confirms that the regression was significant between dependent and independent variables.

\section{Theme III :Differences in insomnia according to variable}

Table (6): The $\mathrm{T}$ test for differences between variables

\begin{tabular}{|c|c|c|c|c|c|c|c|c|}
\hline & \multicolumn{2}{|c|}{ Unstandardized Coefficients } & \multirow{2}{*}{$\begin{array}{c}\text { Standardized } \\
\text { Coefficients Beta }\end{array}$} & \multirow[t]{2}{*}{$\mathrm{t}$} & \multirow[t]{2}{*}{ sig } & \multicolumn{3}{|c|}{ Correlations } \\
\hline & B & Std. Error & & & & $\begin{array}{l}\text { Zero- } \\
\text { order }\end{array}$ & Partial & Part \\
\hline (Constant) & 83.382 & 4.124 & & 20.221 & .000 & & & \\
\hline $\begin{array}{l}\text { number of } \\
\text { accounts }\end{array}$ & 3.546 & .356 & .466 & 9.954 & .000 & .383 & .467 & .452 \\
\hline GPA & - & 1.151 & $-.273-$ & - & .0 & - & $-.301-$ & $-.270-$ \\
\hline $\begin{array}{l}\text { preferred } \\
\text { accounts }\end{array}$ & $\begin{array}{l}6.846- \\
1.733\end{array}$ & .400 & .202 & $\begin{array}{l}5.947- \\
4.337\end{array}$ & $\begin{array}{c}00 \\
.000\end{array}$ & $\begin{array}{l}.228- \\
.132\end{array}$ & .224 & .197 \\
\hline
\end{tabular}

After confirming that there is a relationship between all independent variables and the dependent variable, it is necessary to identify which independent variables have the greatest effect, as shown in Table (6) that the number of accounts is the variable with the greatest effect and the degree of $\mathrm{T}=9.954$, significance level .000 .

Table (7): The Differences in insomnia between groups of number of accounts

\begin{tabular}{|c|c|c|c|c|c|c|c|c|}
\hline \multirow[b]{2}{*}{$\begin{array}{l}\text { number of } \\
\text { accounts }\end{array}$} & \multirow[b]{2}{*}{$\mathrm{N}$} & \multirow[b]{2}{*}{ Mean } & \multicolumn{5}{|c|}{$\begin{array}{l}\text { 95\% Confidence Interval for } \\
\text { Mean }\end{array}$} & \multirow[b]{2}{*}{ Maximum } \\
\hline & & & $\begin{array}{c}\text { Std. } \\
\text { Deviation } \\
\end{array}$ & $\begin{array}{l}\text { Std. } \\
\text { Error }\end{array}$ & $\begin{array}{l}\text { Lower } \\
\text { Bound } \\
\end{array}$ & $\begin{array}{l}\text { Upper } \\
\text { Bound } \\
\end{array}$ & Minimum & \\
\hline 1 & 54 & 76.17 & 8.312 & 1.131 & 73.90 & 78.44 & 66 & 92 \\
\hline 2 & 27 & 75.33 & 19.377 & 3.729 & 67.67 & 83.00 & 59 & 102 \\
\hline 3 & 63 & 78.14 & 7.742 & .975 & 76.19 & 80.09 & 62 & 87 \\
\hline 4 & 72 & 77.75 & 6.675 & .787 & 76.18 & 79.32 & 71 & 92 \\
\hline 5 & 48 & 93.63 & 12.931 & 1.866 & 89.87 & 97.38 & 77 & 117 \\
\hline 6 & 90 & 86.07 & 14.967 & 1.578 & 82.93 & 89.20 & 65 & 109 \\
\hline 7 or more & 6 & 105.00 & 4.382 & 1.789 & 100.40 & 109.60 & 101 & 109 \\
\hline Total & 360 & 82.05 & 13.416 & .707 & 80.66 & 83.44 & 59 & 117 \\
\hline
\end{tabular}

This result shows differences in the level of insomnia according to the number of accounts on social media, using (ANOVA) one-way analysis of variance, to explain the difference between the groups of account numbers. It is clear from Table (7) the difference between the group averages, and the highest mean for the seventh group that represents social media users who have seven accounts and more. The sum of squares between groups $=$ 16423.536 , within groups $=48195.564$, the value of $\mathrm{F}=20.049$, and degree of significance $=.000$, which confirm the presence of statistically significant differences. 
Table (8): Post -Hoc Multiple Comparisons to the difference between groups of account numbers

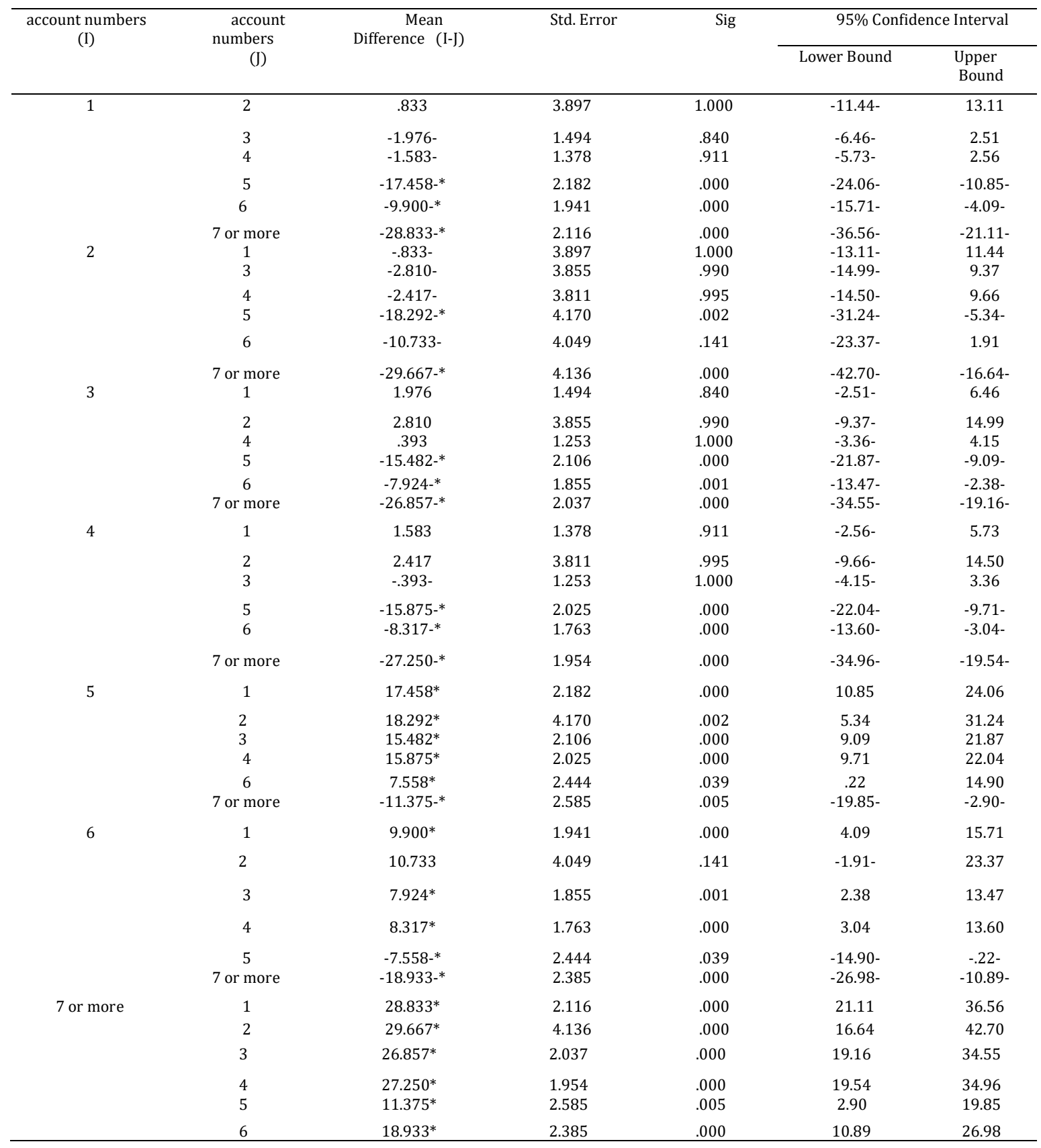

To confirm the largest difference between groups, Post -Hoc Multiple Comparisons the Games-Howell test was used as shown in Table (8). It becomes clear that the seventh group is the largest difference, at the significance level $=0.05$, as shown in Figure (1). 


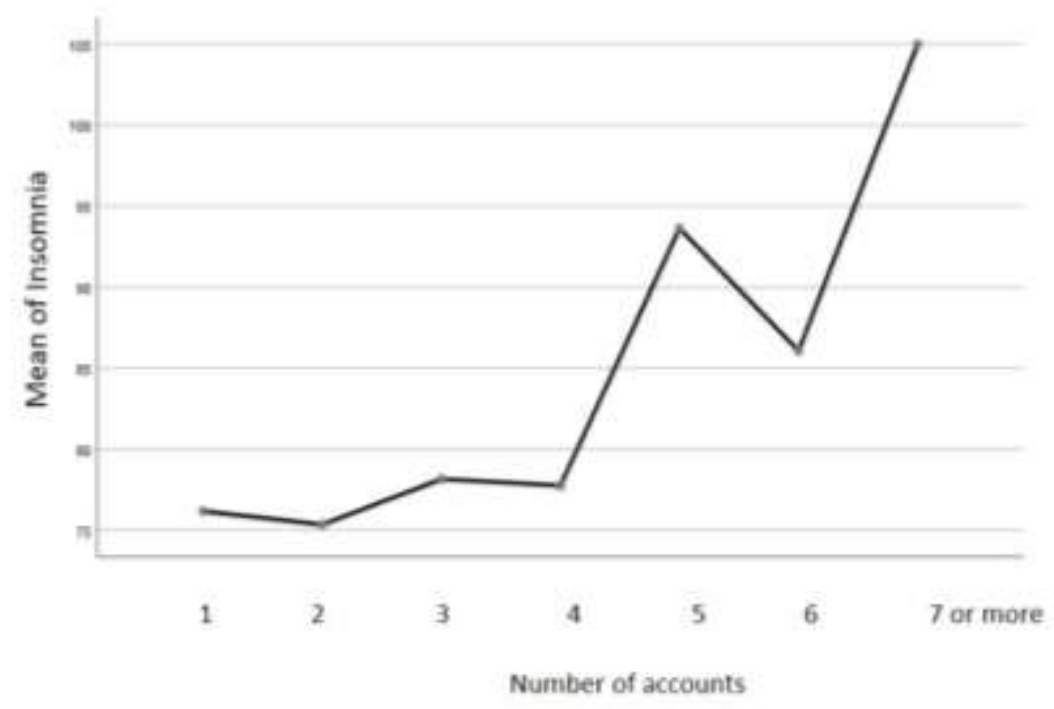

Figure (1): Differences in insomnia depending on the number of accounts

Table (9): Differences in insomnia depending on preferred account

\begin{tabular}{|c|c|c|c|c|c|c|c|c|}
\hline \multirow[b]{2}{*}{ preferred account } & \multirow[b]{2}{*}{$\mathrm{N}$} & \multirow[b]{2}{*}{ Mean } & \multicolumn{6}{|c|}{$\begin{array}{l}\text { 95\% Confidence Interval for } \\
\text { Mean }\end{array}$} \\
\hline & & & $\begin{array}{c}\text { Std. } \\
\text { Deviation }\end{array}$ & $\begin{array}{l}\text { Std. } \\
\text { Error }\end{array}$ & Lower Bound & $\begin{array}{l}\text { Upper } \\
\text { Bound }\end{array}$ & Minimum & Maximum \\
\hline Instagram & 135 & 83.53 & 14.815 & 1.275 & 81.01 & 86.06 & 59 & 117 \\
\hline Twitter & 81 & 82.78 & 12.708 & 1.412 & 79.97 & 85.59 & 66 & 109 \\
\hline Snapchat & 90 & 74.10 & 9.221 & .972 & 72.17 & 76.03 & 62 & 96 \\
\hline Bath & 9 & 91.00 & .000 & .000 & 91.00 & 91.00 & 91 & 91 \\
\hline Whatsapp & 18 & 78.50 & 1.543 & .364 & 77.73 & 79.27 & 77 & 80 \\
\hline YouTube & 18 & 96.50 & 4.630 & 1.091 & 94.20 & 98.80 & 92 & 101 \\
\hline Games sites & 9 & 102.00 & .000 & .000 & 102.00 & 102.00 & 102 & 102 \\
\hline Total & 360 & 82.05 & 13.416 & .707 & 80.66 & 83.44 & 59 & 117 \\
\hline
\end{tabular}

This result clarifies the differences in insomnia according to the preferred account, using the one-way (ANOVA) analysis of the difference between the groups of favorite user accounts, and it is clear from Table (9), the difference between the group averages accordingly, it is found that YouTube, Bath, and gaming sites are the most preferred, and a group Gaming sites above average 102.00, the sum of squares between groups $=14316.400$, inside groups $=50302.700$, and the value of $\mathrm{F}=16.744$, at the degree of significance $=.000$, which confirms the presence of statistically significant differences.

Table (10): Post -Hoc Multiple Comparisons to the difference between groups the preferred account

\begin{tabular}{|c|c|c|c|c|c|c|}
\hline \multirow{2}{*}{$\begin{array}{l}\text { account numbers } \\
\text { (I) }\end{array}$} & \multirow{2}{*}{$\begin{array}{c}\text { account numbers } \\
\text { (J) }\end{array}$} & \multirow{2}{*}{$\begin{array}{c}\text { Mean Difference } \\
(\mathrm{I}-\mathrm{J})\end{array}$} & \multirow[t]{2}{*}{ Std. Error } & \multirow[t]{2}{*}{ Sig } & \multicolumn{2}{|c|}{ 95\% Confidence Interval } \\
\hline & & & & & Lower Bound & $\begin{array}{l}\text { Upper } \\
\text { Bound }\end{array}$ \\
\hline \multirow[t]{6}{*}{ Instagram } & Twitter & .756 & 1.903 & 1.000 & $-4.91-$ & 6.43 \\
\hline & Snapchat & $9.433^{*}$ & 1.603 & .000 & 4.66 & 14.20 \\
\hline & Bath & $-7.467-*$ & 1.275 & .000 & $-11.28-$ & $-3.65-$ \\
\hline & Whatsapp & $5.033^{*}$ & 1.326 & .004 & 1.07 & 9.00 \\
\hline & YouTube & $-12.967-*$ & 1.678 & .000 & $-18.05-$ & $-7.88-$ \\
\hline & Games sites & $-18.467-*$ & 1.275 & .000 & $-22.28-$ & -14.65 \\
\hline \multirow[t]{2}{*}{ Twitter } & Instagram & $-.756-$ & 1.903 & 1.000 & $-6.43-$ & 4.91 \\
\hline & Snapchat & $8.678^{*}$ & 1.714 & .000 & 3.55 & 13.80 \\
\hline
\end{tabular}




\begin{tabular}{|c|c|c|c|c|c|c|}
\hline & Bath & $-8.222-^{*}$ & 1.412 & .000 & $-12.49-$ & $-3.95-$ \\
\hline & Whatsapp & 4.278 & 1.458 & .062 & $-.12-$ & 8.68 \\
\hline & YouTube & $-13.722-^{*}$ & 1.785 & .000 & $-19.13-$ & $-8.32-$ \\
\hline & Games sites & $-19.222-^{*}$ & 1.412 & .000 & -23.49 & $-14.95-$ \\
\hline \multirow[t]{6}{*}{ Snapchat } & Instagram & $-9.433-^{*}$ & 1.603 & .000 & $-14.20-$ & $-4.66-$ \\
\hline & Twitter & $-8.678-^{*}$ & 1.714 & .000 & $-13.80-$ & $-3.55-$ \\
\hline & Bath & $-16.900-^{*}$ & .972 & .000 & $-19.83-$ & $-13.97-$ \\
\hline & Whatsapp & $-4.400-^{*}$ & 1.038 & .001 & $-7.52-$ & $-1.28-$ \\
\hline & YouTube & $-22.400-^{*}$ & 1.462 & .000 & -26.89 & $-17.91-$ \\
\hline & Games sites & $-27.900-^{*}$ & .972 & .000 & $-30.83-$ & $-24.97-$ \\
\hline \multirow[t]{6}{*}{ Bath } & Instagram & $7.467^{*}$ & 1.275 & .000 & 3.65 & 11.28 \\
\hline & Twitter & $8.222^{*}$ & 1.412 & .000 & 3.95 & 12.49 \\
\hline & Snapchat & $16.900^{*}$ & .972 & .000 & 13.97 & 19.83 \\
\hline & Whatsapp & $12.500^{*}$ & .364 & .000 & 11.29 & 13.71 \\
\hline & YouTube & $-5.500-^{*}$ & 1.091 & .002 & $-9.13-$ & $-1.87-$ \\
\hline & Games sites & $-11.000-$ & .000 & . & $-11.00-$ & $-11.00-$ \\
\hline \multirow[t]{6}{*}{ Whatsapp } & Instagram & $-5.033-^{*}$ & 1.326 & .004 & $-9.00-$ & $-1.07-$ \\
\hline & Twitter & $-4.278-$ & 1.458 & .062 & $-8.68-$ & .12 \\
\hline & Snapchat & $4.400^{*}$ & 1.038 & .001 & 1.28 & 7.52 \\
\hline & Bath & $-12.500-^{*}$ & .364 & .000 & $-13.71-$ & -11.29 \\
\hline & YouTube & $-18.000-^{*}$ & 1.150 & .000 & $-21.74-$ & $-14.26-$ \\
\hline & Games sites & $-23.500-^{*}$ & .364 & .000 & $-24.71-$ & -22.29 \\
\hline \multirow[t]{6}{*}{ YouTube } & Instagram & $12.967^{*}$ & 1.678 & .000 & 7.88 & 18.05 \\
\hline & Twitter & $13.722^{*}$ & 1.785 & .000 & 8.32 & 19.13 \\
\hline & Snapchat & $22.400^{*}$ & 1.462 & .000 & 17.91 & 26.89 \\
\hline & Bath & $5.500^{*}$ & 1.091 & .002 & 1.87 & 9.13 \\
\hline & Whatsapp & $18.000^{*}$ & 1.150 & .000 & 14.26 & 21.74 \\
\hline & Games sites & $-5.500-^{*}$ & 1.091 & .002 & $-9.13-$ & $-1.87-$ \\
\hline \multirow[t]{6}{*}{ Games sites } & Instagram & $18.467^{*}$ & 1.275 & .000 & 14.65 & 22.28 \\
\hline & Twitter & $19.222^{*}$ & 1.412 & .000 & 14.95 & 23.49 \\
\hline & Snapchat & $27.900^{*}$ & .972 & .000 & 24.97 & 30.83 \\
\hline & Bath & 11.000 & .000 & . & 11.00 & 11.00 \\
\hline & Whatsapp & $23.500^{*}$ & .364 & .000 & 22.29 & 24.71 \\
\hline & YouTube & $5.500^{*}$ & 1.091 & .002 & 1.87 & 9.13 \\
\hline
\end{tabular}

To ensure the group with the greatest difference between groups, the Games-Howell test was used as shown in Table (10), It becomes clear that the group of game site users has the biggest difference, at a significance level = 0,000. See Figure (2). 


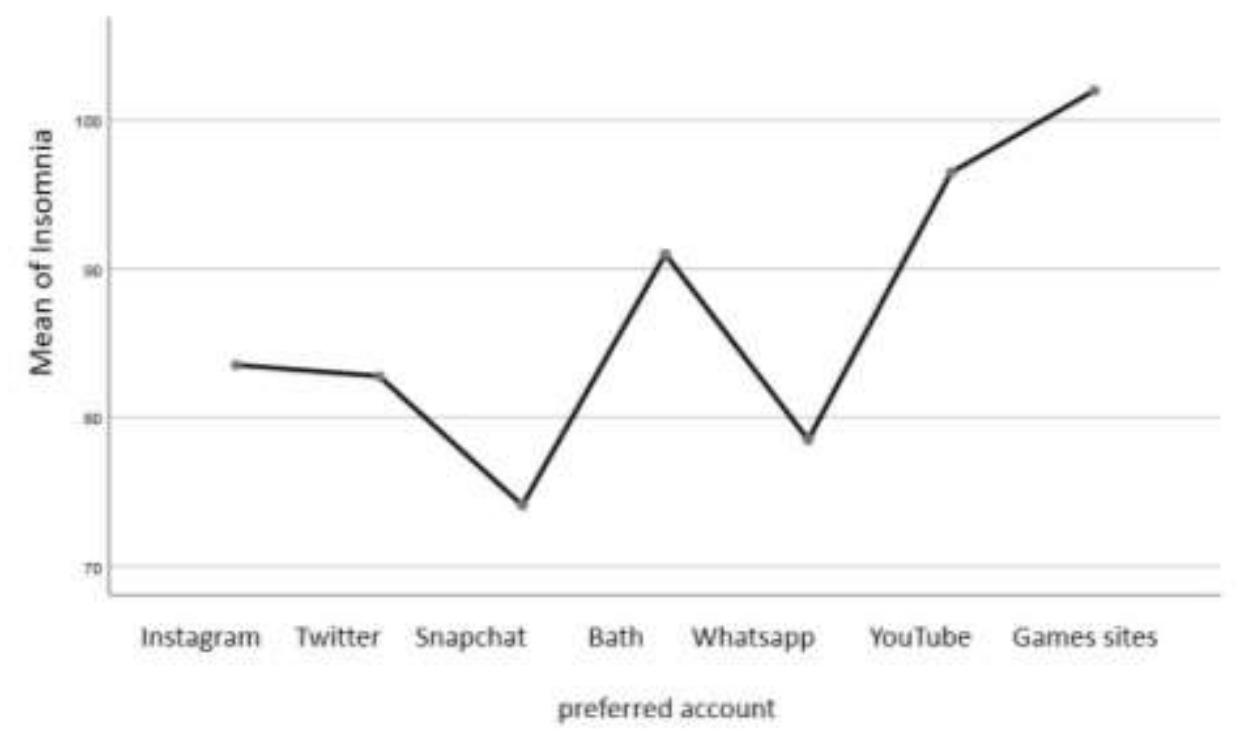

Figure (2): Differences in mean of insomnia according to the preferred calculation

\section{Theme IV: Differences in excessive use depending on the demographic variable}

Table (11): The differences in excessive use according to marital status and specialization, and interaction between them

\begin{tabular}{cccccc}
\hline Source & $\begin{array}{c}\text { Type III } \\
\text { Sum of Squares }\end{array}$ & $\mathrm{df}$ & Mean Square & $\mathrm{F}$ & Sig \\
& $82682.921 \mathrm{a}$ & 6 & 13780.487 & 21.534 & .000 \\
\hline Corrected Model & 1119544.984 & 1 & 1119544.984 & 1749.48 & .000 \\
Intercept & 63362.002 & 3 & 21120.667 & 73.005 & .000 \\
marital status & 46645.993 & 2 & 23322.997 & 36.446 & .000 \\
Specialization & 33786.422 & 1 & 33786.422 & 52.797 & .000 \\
marital status* & & & & \\
Specialization & 225894.454 & 353 & 639.928 & & \\
Error & 4895253.000 & 360 & & & \\
Total & 308577.375 & 359 & & & \\
Corrected Total & & & & & \\
\hline
\end{tabular}

The differences in the excessive use of social media were identified according to the marital status and specialization variables, and the interaction between them was illustrated by using the ANOVA tow - way analysis of variance.

Table (11) shows that there are statistically significant differences in marital status, $\mathrm{F}=33.005$, and the level of significance $=.000$, while the differences in the specialization are a function, $\mathrm{F}=36.446$, and significance $=.000$, in addition to the interaction between them significance at the level of .000 .

Table (12): Comparing the means between the Marital status and specialty variables

\begin{tabular}{cccc}
\hline Marital status & specialization & Mean & Std.Deviation \\
\hline Single & Humanities & 108.84 & 25.603 \\
& Engineering & 145.00 & .000 \\
& Medical & 108.86 & 32.286 \\
\multirow{3}{*}{ Engaged } & Total & 109.94 & 27.440 \\
& Humanities & 100.50 & 7.717 \\
& Medical & 180.00 & .000 \\
Married & Total & 127.00 & 38.697 \\
& Humanities & 139.67 & 22.716 \\
Divorced & Total & 139.67 & 22.716 \\
& Humanities & 87.00 & .000 \\
& Total & 87.00 & .000 \\
\hline
\end{tabular}

Referring to Table (12) it is clear that the highest mean $=180$, is for engaging in the medical specialization, and the lowest mean $=87$ for divorced women in the discipline of the humanities, as shown in figure (3). 


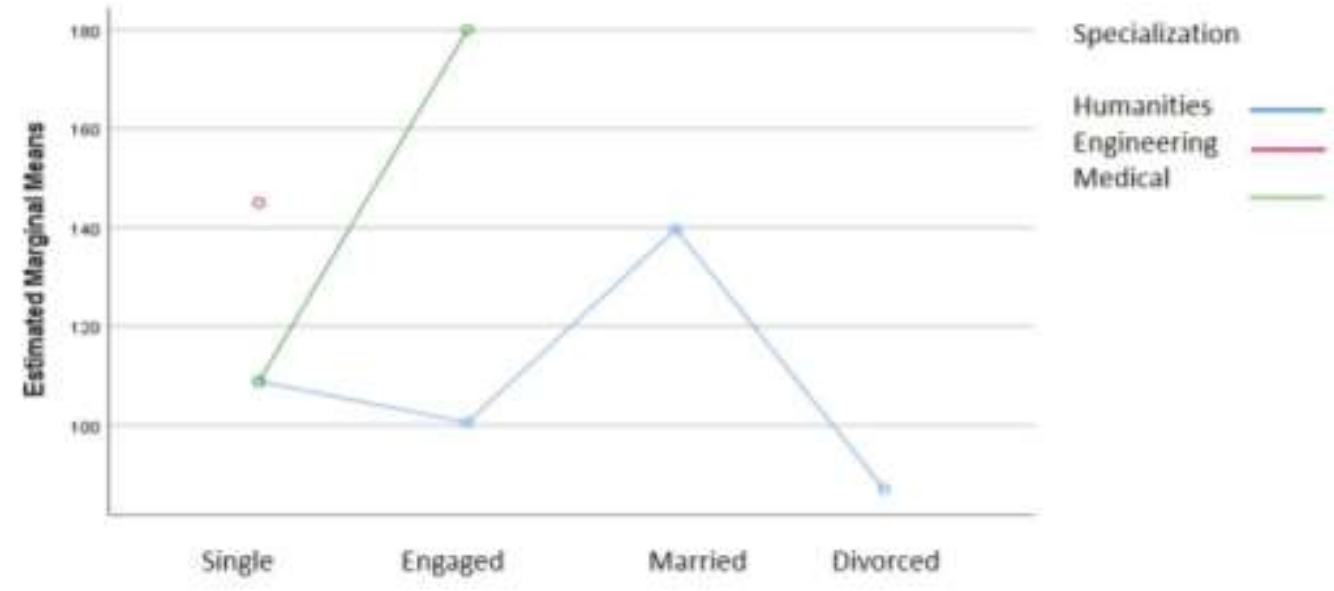

Figure (3): Comparing the means between the marital status and specialty variables

\section{Discussion}

The use of social media applications is related to the accessibility and benefits the user perceives and aims to achieve, whether they are related to social interactions or knowledge (Mäntymäki and Riemer 2011). Although this benefit occurs, compulsive use affects academic, social, and physical performance (Vladlena et al, 2018). Many mental disorders have been linked to internet addiction, which is associated with low self-esteem, impulsivity, poor sleep quality, mood disorder, and suicide (Tripathi, 2018). The current study indicated that excessive social media use is positively associated with insomnia and that an increase in the number of social media accounts increases the likelihood of compulsive use. Some specialists suggest that there are commonalities in behavioral addictions, and substance addictions share many aspects (Pontes, Szabo, \& Griffiths, 2015) such as some symptoms (loss of control, difficulty concentrating, life struggles, cravings, and other psychological problems). (Social, Kuss \& Griffiths, 2012). Al-Hilu and his colleagues (2018) conducted a comparative study in several Arab countries on university students, and they showed that increasing daily use of social media is positively associated with symptoms of cyber addiction, and associated with feelings of Jealousy and frustration, which causes psychological distress for students. Lennart Raudsepp's (2019) study confirms that an increasing time in social media usage is associated with an increase in sleep disturbances, in addition to a negative relationship between excessive use and academic achievement, in line with several studies. Larose et al. (2011) concluded that compulsive use has negative academic and interpersonal effects, and occupational consequences, which leads to diminished self-regulation and poor compatibility in university life. In addition, social media addiction often results in wasted time and reduced work and academic performance (Masur et al, 2014). There is also a relationship between Internet addiction and a lack of other interests (Al-Homsi, 2010).

The current study found that students who suffer from high insomnia are those who use multiple accounts in addition to their preference for gaming sites, these sites combine contact with others and make friends and enjoy games that contain many visual and auditory effects, allowing immersion in them. Jana spilkov (2017) study revealed a correlation between excessive use of social media and gaming site use among high school students in the Czech Republic. That the constant and frequent use of the Internet to participate in games, often with other players, leads to clinically significant impairment or distress such as tolerance (i.e., spending more time playing), lack of control, and loss of other interests (Kardefelt-Winther et al., 2017). In the study conducted by Nazmus Saquib and colleagues (2017) on expatriate high school students in Saudi Arabia, it was found that 75\% spent more than two hours in front of screens per day, and $20 \%$ slept less than 5 hours a night. (16\%) were addicted to video games, and those who reported gaming use of 2-3 hours, 4-5 hours, or -6 hours experienced greater distress than those who reported spending one hour in front of a screen daily or less, and females are the most affected by psychological distress and lack of sleep hours. This result is consistent with the study conducted in Germany, which showed that $3 \%$ of students who indulged in internet games for long periods reported sleep problems and had low school grades (Rehbein, Kliem, Baier, Mößle, \& Petry, 2015). Spending more time on social media leads to internet game addiction, disrupts the normal sleep pattern, and leads to more interruptions during sleep (Hale, L., \& Guan, S. 2015).

Singles are also positively associated with addiction to the use of social media and game sites (Andreassen, etc., 2016). This may be due to that single and engaged students have more free time, lack of household chores to fulfill duties as married women do. As indicated by Al-Fadhel (2013) in his study at King Saud University, students that the most important motivations for using social media are entertainment, exploration, acquaintance, and communication with others. Social and emotional motivation has an important role in overuse, $87 \%$ of Al- Petra University students used social media for entertainment, and $86 \%$ of them achieved emotional satisfaction (Al-

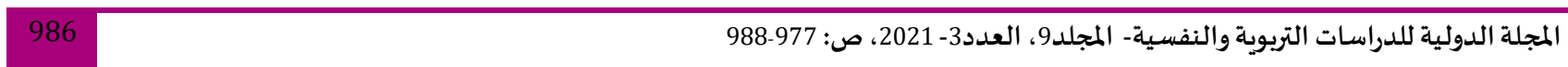


Bashabsha, 2013). Accordingly, social media sites allow engaged students to share feelings with their partners, so they are the most users.

\section{Conclusion}

The study concluded that excessive use of social media makes the female college students suffer from insomnia. The increasing use, multiplication of accounts, and gaming sites play a prominent role in increasing insomnia. The most affected by these factors are the engaged students.

\section{Study recommendations:}

- Providing counseling programs for students related to the impact of excessive use on various aspects of life.

- Take advantage of students' interest in social networking sites, especially interactive games sites, and enrich them with knowledge.

- Conducting studies dealing with psychological disorders such as anxiety and depression among students who use excessive social media sites.

\section{Acknowledgment:}

The authors thank all participants for sharing their experiences and insights.

\section{Declaration of Conflicting Interests:}

The author declared no potential conflicts of interest with respect to the research, authorship, and/or publication of this article.

\section{Reference}

1. Andreassen, C. S., Billieux, J., Griffiths, M. D., Kuss, D. J., Demetrovics, Z., Mazzoni, E., \& Pallesen, S. (2016). The relationship between addictive uses of social media and video games and symptoms of psychiatric Disorders: A Large-Scale CrossSectional Study. Psychology of Addictive Behaviors. viors (C) 2016 American Psychological Association 2016, V. American Psychological Association, http://dx.doi.org/10.1037/adb0000160

2. Ericsson. Ericsson Mobility Report. Stockholm: Ericsson. Available online: https://d110erj1750600.cloudfront. net/upload/images/06_2017/170615153722.pdf (accessed on 23 September 2019).

3. Cao, X.; Yu, L. (2019). Exploring the influence of excessive social media use at work: A threedimension usage perspective. Int. J. Inf. Manag, 46: 83-92, https://doi.org/10.1016/j.ijinfomgt.2018.11.019.

4. Settanni, M.; Marengo, D.; Fabris, M.A. \& Longobardi, C. (2018). The interplay between ADHD symptoms and time perspective in addictive social media use: A study on adolescent Facebook users. Child Youth Serv. Rev, 89: 165-170, https://doi.org/10.1016/j.childyouth.2018.04.031.

5. Al-Bashabsha, w. (2013). The motivations of using social networking by the students of Jordanian Universities. university of petra. Jordan. https://2u.pw/nPMnK.

6. Al-Fadhel, S. (2013). Dimensions of the use of social networks by Saudi youth. King Saud University, Riyadh. https://2u.pw/Zs]Xf.

7. Al-Helou,C. Greg,T. Korkmaz,J \& Youssef, E. (2018). Social networking sites and their impact on the psychological state of university students, a multi-country comparative study. International Journal of Educational \& Psychological Studies, 3(2): 235-268, https://2u.pw/ZGoro.

8. American Psychiatric Association. (2013). Diagnostic and Statistical Manual of Mental Disorders, Fifth Edition: DSM-5 (American Psychiatric Association).

9. American Academy of Sleep Medicine. (2014). International Classification of Sleep Disorders 3rd edt (American Academy of Sleep Medicine).

10. Bakotic, M., Radosevic-Vidacek, B., \& Koscec Bjelajac, A. (2016). Morningness-eveningness and daytime functioning in university students: the mediating role of sleep characteristics. Journal of Sleep Research, 26(2): 210-218. doi:10.1111/jsr.12467.

11. Bhat, S., Pinto-Zipp, G., Upadhyay, H., \& Polos, P. G. (2018). “To sleep, perchance to tweet”: in-bed electronic social media use and its associations with insomnia, daytime sleepiness, mood, and sleep duration in adults. Sleep Health, 4(2): 166173. doi: 10.1016/j.sleh.2017.12.004.

12. Chaffey, D. (2020). Global social media research summary 2020. Smart insights, https://2u.pw/CILbW.

13. Charles M. Morin, Christopher L. Drake, Allison G. Harvey, Andrew D. Krystal, Rachel Manber, Dieter Riemann, Kai Spiegelhalder. (2015). Insomnia disorder. Nature Reviews Disease Primers, 1. doi:10.1038/nrdp.2015.26.

14. Charlotte Kirk-Patrick Roxanne Steijn. (2014). How Much of an Effect Does Social Media Have on Insomnia and Depression. Nottingham University. medlink-uk.net.

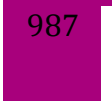

المجلة الدولية للدراسات التربوية والنفسية- المجلد9، العدد3- 2021، ص: 977-988 
15. Hale, L., \& Guan, S. (2015). Screen time and sleep among school-aged children and adolescents: A systematic literature review. Sleep Medicine Reviews, 21: 50-58. http:// dx.doi.org/10.1016/j.smrv.2014.07.007.

16. Hanprathet, N., Manwong, M., Khumsri, J., Yingyeun, R., \& Phanasathit, M. (2015). Facebook addiction and its relationship with mental health among Thai high school students. Journal of the Medical Association of Thailand, 98(3): S81-90.

17. JANA SPILKOV, PAVLA CHOMYNOV \& LADISLAV CSÉMY. (2017). Predictors of excessive use of social media and excessive online gaming in Czech teenagers. Journal of Behavioral Addictions 6(4): 611-619. DOI: 10.1556/2006.6.2017.064.

18. Kardefelt-Winther, D., Heeren, A., Schimmenti, A., van Rooij, A., Maurage, P., Carras, M., ... Billieux, J. (2017). How can we conceptualize behavioural addiction without pathologizing common behaviours? Addiction, 112(10): 1709-1715. http://dx.doi.org/ 10.1111/add.13763.

19. Kazdin, A. E. (2007). Mediators and Mechanisms of Change in Psychotherapy Research. Annual Review of Clinical Psychology, 3(1): 1-27. doi: 10.1146/annurev.clinpsy.3.022806.091432.

20. Kraemer, H. C., Stice, E., Kazdin, A., Offord, D., \& Kupfer, D. (2001). How Do Risk Factors Work Together? Mediators, Moderators, and Independent, Overlapping, and Proxy Risk Factors. American Journal of Psychiatry, 158(6): 848-856. doi:10.1176/appi.ajp.158.6.848

21. Kuss, D. J., \& Griffiths, M. D. (2012). Internet gaming addiction: A systematic review of empirical research. International Journal of Mental Health and Addiction, 10(2): 278-296, doi:10.1007/ s11469-011-9318-5.

22. Larose, Robert, Donghee Yvette Wohn, N. Ellison, \& Charles Steinfield. (2011). Facebook Fiends Compulsive Social Networking and Adjustment to College. In IADIS International Conference ICT, 3-10. Rome, Italy: IADIS

23. Lennart Raudsepp. (2019). Brief report: Problematic social media use and sleep disturbances are longitudinally associated with depressive symptoms in adolescents. Journal of Adolescence. 76. https://doi.org/10.1016/j.adolescence.2019.09.005.

24. Masur, Philipp K., Leonard Reinecke, Marc Ziegele, \& Oliver Quiring. (2014). The Interplay of Intrinsic Need Satisfaction and Facebook Specific Motives in Explaining Addictive Behavior on Facebook. Computers in Human Behavior, 39: 376386, https://doi.org/10.1016/j.chb.2014.05.047.

25. Pontes, H. M., Szabo, A., \& Griffiths, M. D. (2015). The impact of Internet-based specific activities on the perceptions of Internet addiction, quality of life, and excessive usage: A crosssectional study. Addictive Behaviors Reports, 1: 19-25. doi:10. 1016/j.abrep.2015.03.002.

26. Rehbein, F., Kliem, S., Baier, D., Mößle, T., \& Petry, N. M. (2015). Prevalence of Internet gaming disorder in German adolescents: Diagnostic contribution of the nine DSM-5 criteria in a state-wide representative sample. Addiction, 110(5): 842-851, http://dx. doi.org/10.1111/add.12849.

27. Saquiba,N., Saquibb,J., Wahida,A., Ahmeda,A., Dhuhayra,H., Zaghloula,M., Ewida, M.,\& Al-Mazroua,A. (2017). Video game addiction and psychological distress among expatriate adolescents in Saudi Arabia. Addictive Behaviors Reports. Published by Elsevier B.V. http://dx.doi.org/10.1016/j.abrep.2017.09.003.

28. Saudi Ministry of Communications and Information Technology. (2020). https://www.mcit.gov.sa/ar/mediacenter/news/89698.

29. Tripathi, A. (2018). Impact of Internet Addiction on Mental Health: An Integrative Therapy Is Needed. Integrative Medicine International. Published by karger AG,Basel. D0I:10.1159/000491997.

30. Vladlena Bensona, Chris Handb \& Richard Hartshorne. (2018). How compulsive use of social media affects performance: insights from the UK by purpose of use. Behaviour \& Information Technology, DOI: 10.1080/0144929X.2018.1539518.

31. Walsh, J. L., Fielder, R. L., Carey, K. B., \& Carey, M. P. (2013). Female College Students' Media Use and Academic Outcomes. Emerging Adulthood, 1(3): 219-232, doi:10.1177/2167696813479780.

32. Back, M.; Stopfer, J.M.; Vazire, S.; Gaddis, S.; Schmukle, S.C.; Egloff, B.; Gosling, S.D. (2010). Facebook profiles reflect actual personality, not self-idealization. Psychol. Sci., 20. 